TRANSACTIONS OF THE

AMERICAN MATHEMATICAL SOCIETY

Volume 360, Number 5, May 2008, Page 2809

S 0002-9947(07)04652-1

Article electronically published on December 11, 2007

\title{
ERRATUM TO “CLASSIFYING SUBCATEGORIES OF MODULES"
}

\author{
MARK HOVEY
}

In my paper [Hov01], Theorem 5.2 is incorrect, as pointed out to me by Henning Krause. In the proof of that theorem, I assert that "The composition $f \alpha$ is proved to be an isomorphism" by Neeman. In fact, the map Neeman uses is not $f \alpha$, so the argument is incorrect. A counterexample to Theorem 5.2, and a corrected version, is provided by Krause in [Kra].

\section{REFERENCES}

[Hov01] Mark Hovey, Classifying subcategories of modules, Trans. Amer. Math. Soc. 353 (2001), no. 8, 3181-3191 (electronic). MR1828603 (2002i:13007)

[Kra] Henning Krause, Thick subcategories of modules over Noetherian rings (with an appendix by Srikanth Iyengar), to appear in Math. Annalen.

Department of Mathematics, Wesleyan University, Middletown, Connecticut 06459

E-mail address: hovey@member.ams.org

Received by the editors September 28, 2007.

2000 Mathematics Subject Classification. Primary 13C05, 18E30, 18 G35.

(C) 2007 American Mathematical Society Reverts to public domain 28 years from publication 